\title{
CONCHA BULLOSA MUCOPYOCELE: A CASE REPORT
}

\author{
Kamran Sari, Zeliha Kapusuz Gencer, Yunus Kantekin
}

\author{
Bozok University School of Medicine, Ear Nose \& Throat Department, Yozgat, Turkey
}

\begin{abstract}
Summary: Concha bullosa (CB) is among the most common anatomic variations of sinonasal anatomy. Although usually asymptomatic, $\mathrm{CB}$ can occasionally cause nasal obstruction or headache. Obstructions within the mucociliary transport system can develop into a mucocele or mucopyocele. A 48-year-old female, with a history of progressive headache and nasal obstruction, was referred to our department. Paranasal sinus tomography revealed a nasal mass in the left nasal cavity resembling a mucopyocele in the middle turbinate. Under general anesthesia, the purulent material was aspirated, and the lateral part of the left turbinate was resected. Mucopyoceles are common within the paranasal sinuses, but uncommon with $\mathrm{CB}$; thus, they should be considered in patients with a large hyperemic nasal mass.
\end{abstract}

Keywords: Concha Bullosa; Mucopyocele; Mucocele; Nasal obstruction

\section{Introduction}

Concha bullosa (CB) is among the most common anatomic variations of paranasal sinuses. $\mathrm{CB}$ is defined as pneumatization of the middle, inferior, or superior turbinate (1). Although typically asymptomatic, CB can sometimes lead to nasal obstructions or headache due to contact with the lateral nasal wall. The CB mucociliary transport system drains into the frontal recess or the middle meatus over the sinus lateralis (2). Obstruction of a CB can result in a mucocele. Secondary infections that develop over a mucocele are referred to as mucopyoceles (3). We report herein a case of a CB-related mucopyocele with a large hyperemic nasal mass that caused nasal obstruction and headache, and was treated endoscopically.

\section{Case report}

A 48-year-old female with a history of progressive headache and nasal obstruction was referred to our ear nose and throat department. The patient that has not got any complaint previously reported increasingly severe and frequent nasal obstruction and headache attacks during the previous week. She did not mention postnasal drip and olfactory impairment. On nasal endoscopic examination, a hyperemic mass that invaded the left nasal cavity was observed. Paranasal sinus tomography (CT) revealed a lesion in the left nasal cavity resembling a mucopyocele in the middle turbinate (Figure 1). CT sections of the paranasal sinuses were normal (Figure 2). Based on the clinical and radiologic findings, we decided to perform endoscopic $\mathrm{CB}$ resection. The middle turbinate included a large amount of purulent material (Figure 3), which was subsequently aspirated; the lateral part of the left turbinate was resected. Antibiotic therapy was provided using intravenous ampicillin/sulbactam at a dose of $4 \mathrm{~g}$ per day. Cultures were taken during surgery. Meticilin-sensitive Staphylococcus Aureus was detected on the culture; 10-day antibiotic therapy was started promptly. During the postoperative period, the patient's complaints subsided and she experienced marked improvement. The excision material was reported as mucocele at pathological examination. During the following 9 months, the patient developed no additional problems, and there was no recurrent pathology on her nasal endoscopic examination (Figure 4). Informed consent was obtained from the patient before the report was made.

\section{Discussion}

$\mathrm{CB}$, which is principally characterized by pneumatization of the middle turbinate, is among the most common anatomic variations of sinonasal anatomy. The incidence of CB ranges from $14 \%$ to $53 \%$ (4), and it is encountered both unilaterally and bilaterally. Pneumatization of the middle turbinate CB usually arises from anterior or posterior ethmoid cells. CB typically causes no symptoms and is usually diagnosed incidentally on CT sections. Bolger et al. (5) classifies CB pneumatization according to its location; when it involves the vertical lamella it is referred to as lamellar, whereas involvement of the inferior bulbous segment is referred to as bulbous. When pneumatization involves the entire concha it is referred to as extensive; if it obstructs the sinus ostia nasal obstruction or headache can occur (6). In our patient, nasal obstruction was the main symptom.

A mucocele is a true cyst lined with pseudostratified ciliated columnar epithelium (6); if it becomes infected, it is referred to as a mucopyocele. Mucoceles and mucopy- 


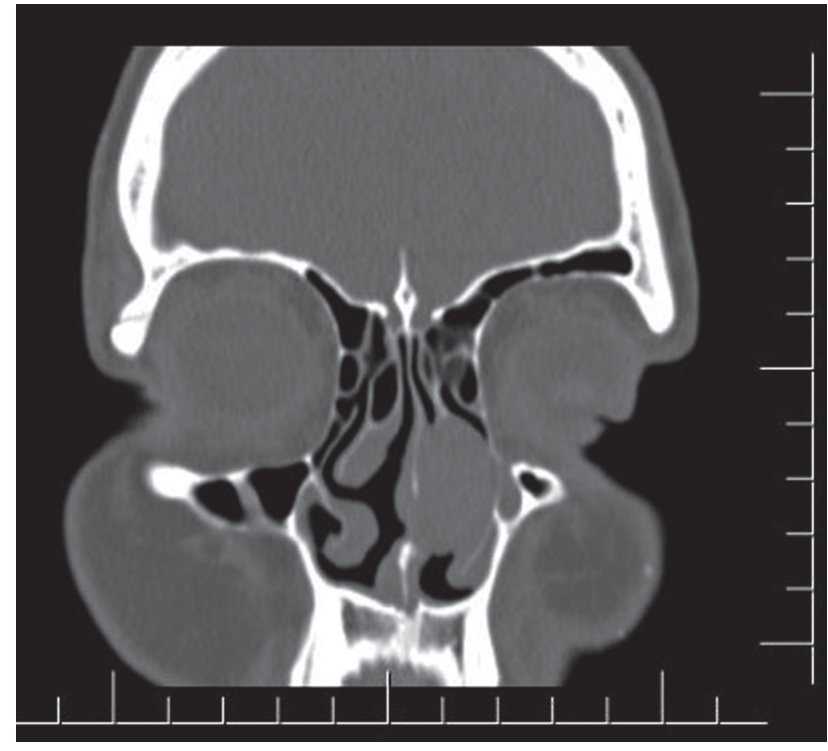

Fig. 1: The mucopyocele filled the left nasal cavity.

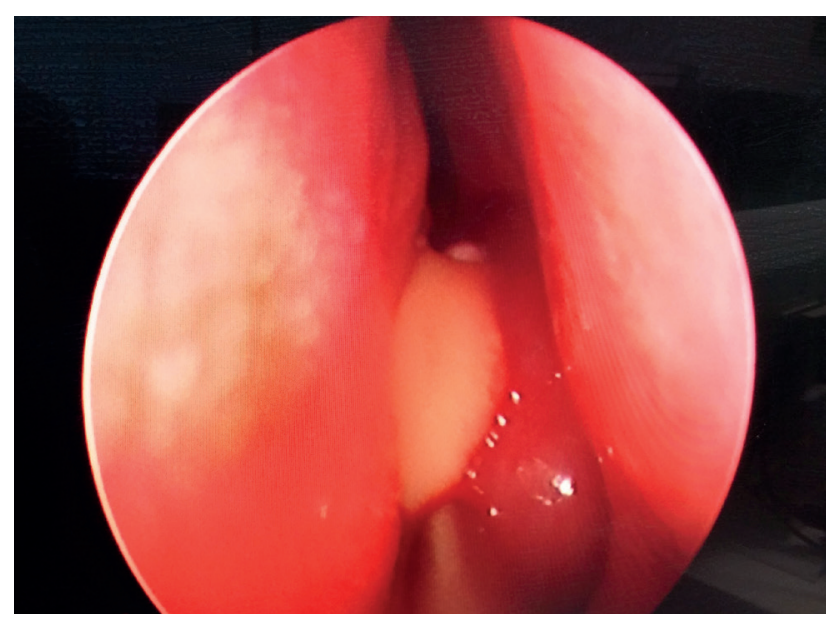

Fig. 3: Purulent secretion filled the middle turbinate.

oceles are uncommon in the $\mathrm{CB}$, with only 10 previous reports of $\mathrm{CB}$ mucoceles or mucopyoceles $(3,6-8)$. Mucoceles of the paranasal sinuses or CB typically develop due to an obstruction in the mucociliary transport system. Nasal trauma or chronic rhinosinusitis may obstruct the sinus ostia. As a result of obstructed mucociliary flow, mucus secretion leads to an expansion of the middle turbinate, which can lead to bone erosion, diplopia, nasal obstruction, or headache. On endoscopic examination a conchal mass is usually seen in the nasal cavity. Axial and coronal CT images provide useful information concerning nasal and paranasal structures (3), which can appear as a mass of soft tissue surrounded by a thin plate of bone that may expand into surrounding structures (9). Magnetic resonance imag-

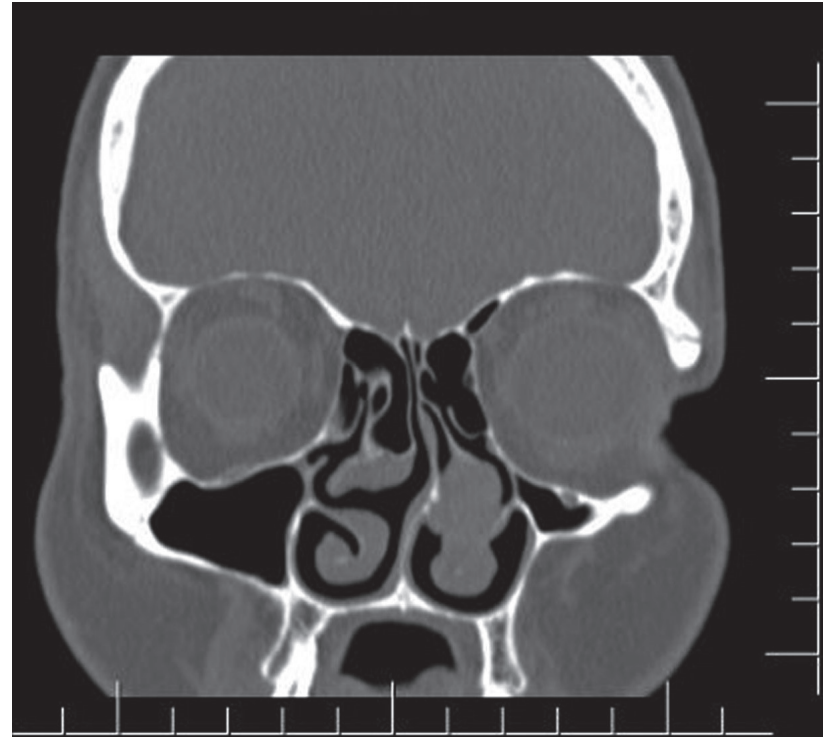

Fig. 2: There was no sign of sinusitis in the paranasal sinuses

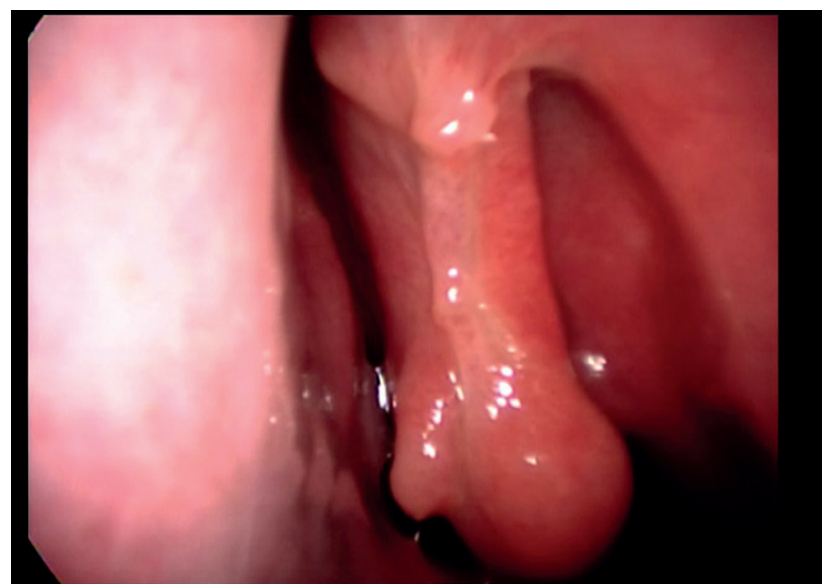

Fig. 4: There was no sign of infection in nasal cavity at endoscopic image in post operative 9 months.

ing can be used if intracranial or intraorbital complications are suspected.

The relationship between $\mathrm{CB}$ and chronic rhinosinusitis remains unclear. In several studies, there were no significant differences in chronic rhinosinusitis incidence between patients with and without $\mathrm{CB}(3,10,11)$. However, other studies report a significantly higher risk in $\mathrm{CB}$ patients (12-14). There have been 10 published cases of CB mucopyoceles, 7 of which describe patients with sinusitis (3). In our case, CT sections of the paranasal sinuses were normal.

In a study by Brook and Frazier (15), aerobic bacteria were identified in only 7 (19\%) of 36 specimens; anaerobic bacteria alone were identified in 15 specimens $(42 \%)$, and mixed aerobic and anaerobic bacteria were observed 
in 14 specimens (39\%). There was no correlation between clinical and medical history, including recent antimicrobial therapy and microbiologic results. We identified the aerobic bacteria Staphylococcus Aureus, and treated it using ampicilin/sulbactam.

The treatment of choice for mucopyoceles is endoscopic $\mathrm{CB}$ resection and drainage. We excised the lateral border of the $\mathrm{CB}$ and aspirated the mucopurulent secretion. Lateral marsupialization, medial marsupialization, crushing, and transverse excision represent other treatment options (16).

\section{Conclusions}

Mucopyoceles are common within the paranasal sinuses but are uncommon with $\mathrm{CB}$, in which surrounding structures may be compressed potentially leading to nasal obstruction or headache. We suggest that CB mucopyoceles should be considered in patients with a large hyperemic nasal mass.

\section{Acknowledgements}

This case report was presented as a poster at the 11th Turkish Rhinology Convention, 2015.

\section{Conflict of interest}

The authors have no conflicts of interest to declare.

\section{References}

1. Ariyurek OM, Balkanci F, Aydingoz U, Onerci M. Pneumatised superior turbinate: a common anatomic variation? Surg Radiol Anat 1996; 18: 137-9.

2. SJ Z. CT of the nasal cavity and paranasal sinuses with emphasis on inflammatory diseases. In: Anand VK PR, edS. Practical Endoscopic Sinus Surgery. New York: McGraw \& Hill, 1992: 42-51.

3. Shihada R, Luntz M. A concha bullosa mucopyocele manifesting as migraine headaches: a case report and literature review. Ear Nose Throat J 2012; 91: 16-8.

4. Stallman JS, Lobo JN, Som PM. The incidence of concha bullosa and its relationship to nasal septal deviation and paranasal sinus disease. AJNR Am J Neuroradiol 2004; 25: 1613-18.

5. Bolger WE, Butzin CA, Parsons DS. Paranasal sinus bony anatomic variations and mucosal abnormalities: CT analysis for endoscopic sinus surgery. The Laryngoscope 1991; 101: 56-64.

6. Cohen SD, Matthews BL. Large concha bullosa mucopyocele replacing the anterior ethmoid sinuses and contiguous with the frontal sinus. Ann Otol Rhinol Laryngol 2008; 117: 15-17.

7. Abdel-Aziz M. Mucopyocele of the concha bullosa presenting as a large nasal mass. J Craniofac Surg 2011; 22: 1141-42.

8. Al-Sebeih KH, Bu-Abbas MH. Concha bullosa mucocele and mucopyocele: a series of 4 cases. Ear Nose Throat J 2014; 93: 28-31.

9. Lloyd G, Lund VJ, Savy L, Howard D. Optimum imaging for mucoceles. J Laryngol Otol 2000; 114: 233-36.

10. Kaygusuz A, Haksever M, Akduman D, Aslan S, Sayar Z. Sinonasal anatomical variations: their relationship with chronic rhinosinusitis and effect on the severity of disease - a computerized tomography assisted anatomical and clinical study. Indian J Otolaryngol Head Neck Surg 2014; 66: 260-6.

11. Nouraei SA, Elisay AR, Dimarco A, et al. Variations in paranasal sinus anatomy: implications for the pathophysiology of chronic rhinosinusitis and safety of endoscopic sinus surgery. J Otolaryngol Head Neck Surg 2009; 38: 32-7.

12. Lloyd GA. CT of the paranasal sinuses: study of a control series in relation to endoscopic sinus surgery. J Laryngol Otol 1990; 104: 477-81.

13. Unlu HH, Akyar S, Caylan R, Nalca Y. Concha bullosa. J Otolaryngol 1994; 23 : 23-27.

14. Zinreich SJ, Mattox DE, Kennedy DW, Chisholm HL, Diffley DM, Rosenbaum AE. Concha bullosa: CT evaluation. J Comput Assist Tomogr 1988; 12: 778-84.

15. Brook I, Frazier EH. The microbiology of mucopyocele. The Laryngoscope 2001 Oct; $111: 1771-3$.

16. Cannon CR. Endoscopic management of concha bullosa. Otolaryngol Head Neck Surg 1994; 110: 449-54.

Received: 05/08/2015

Accepted in revised form: 04/11/2015

Corresponding author:

Kamran Sari, Bozok University School of Medicine, Adnan Menderes Street Number 190, Yozgat/Turkey; e-mail: kamransari@gmail.com 